\title{
ATIVIDADES DE LAZER E SEUS CONTEÚDOS CULTURAIS EM CENTROS DE CONVIVÊNCIA E FORTALECIMENTO DE VÍNCULOS
}

Recebido em: 05/03/2018

Aceito em: 18/12/2018

\author{
Edirlane Soares do Nascimento \\ Juliêta Lopes Fernandes \\ Thaís Norberta Bezerra de Moura \\ Maria Luci Esteves Santiago \\ Universidade Estadual do Piauí \\ Teresina - PI - Brasil
}

RESUMO: O presente estudo objetiva caracterizar as atividades de lazer, seus facilitadores e usuários dos_Centros de Convivência de Teresina-PI. Trata-se de um estudo transversal, com 39 idosos e nove coordenadores, entre agosto e novembro de 2017. Utilizou-se um formulário, com questões objetivas e subjetivas. As atividades de lazer, relacionadas aos aspectos físicos, foram as mais realizadas $(100 \%, n=9)$, em sala/pátio (33\%), e apresentando dificuldades de falta de materiais (33\%). Facilitadores de atividades com formação superior $(45,8 \%)$, com 1 a 2 anos de atuação $(41,6 \%)$ e terceirizados (100\%). Usuários com preferência de atividade física para lazer $(97,4 \%), 1$ a 2 anos de participação (35,9\%), frequência de 2 a 3 vezes/semana $(76,9 \%)$, tendo a saúde $(43,5 \%)$ como motivo de adesão, e os compromissos pessoais $(30,7 \%)$ como limitador da participação.

PALAVRAS CHAVE: Políticas Públicas. Atividades de Lazer. Idoso.

\section{LEISURE ACTIVITIES AND THEIR CULTURAL CONTENT IN CENTERS FOR COEXISTENCE AND STRENGTHENING LINKS}

ABSTRACT: The present study aims to characterize leisure activities, their facilitators and users of Teresina-PI Coexistence Centers. It is a cross-sectional study, with 39 elderly and 9 coordinators, between August and November 2017. A form was used, with objective and subjective questions. The leisure activities related to the physical aspects were the most accomplished $(100 \%, \mathrm{n}=9)$, in room / patio $(33 \%)$, and presenting difficulties of lack of materials (33\%). Facilitators of activities with higher education $(45.8 \%)$, with 1 to 2 years of work $(41.6 \%)$ and outsourced $(100 \%)$. Users with physical activity preference for leisure (97.4\%), 1 to 2 years of participation $(35.9 \%)$, frequency of 2 to 3 times / week $(76.9 \%)$, and health $(43.5 \% \%)$ as a reason for joining, and personal commitments $(30.7 \%)$ as limiting participation.

KEYWORDS: Public Policy. Leisure Activities. Aged. 


\section{Aspectos Introdutórios}

O crescimento da expectativa de vida para os idosos vem aumentando com o passar dos anos (GRDEN et al., 2015; RAMOS et al., 2016). A população brasileira manteve a tendência de envelhecimento dos últimos anos e ganhou 4,8 milhões de idosos desde 2012, superando a marca dos 30,2 milhões em 2017, que corresponde a um crescimento de $18 \%$ desse grupo etário. As mulheres são maioria expressiva nesse grupo, com 16,9 milhões (56\% dos idosos), enquanto os homens idosos são 13,3 milhões (44\% do grupo) (IBGE, 2018).

Esse crescimento torna o envelhecimento uma questão de interesse da sociedade, na proporcionalidade que exige transformações nas instituições públicas, ou que estejam vinculadas às questões voltadas para esse público, e também as políticas públicas relacionadas aos idosos (RAMOS et al., 2016).

Tendo em vista que a representatividade dos idosos é crescente na sociedade, observa-se que a atenção para as discussões sobre políticas públicas, com esse público, ganha visibilidade (DEBERT, 2013; SANTOS et al., 2015), principalmente as que envolvem o envelhecimento ativo e saudável, alicerçadas pelo setor saúde e da assistência social.

Políticas públicas direcionadas para o envelhecimento saudável devem fomentar o empoderamento de pessoas em ambientes amigáveis e culturalmente interessantes, estimular a solidariedade e integração social às mais variadas gerações (DEBERT, 2013).

Nessa perspectiva, as atividades de lazer são consideradas dispositivos de grande potencial para um desenvolvimento saudável de idosos. Alguns estudiosos enfatizam que o lazer contribui para a melhoria da qualidade de vida, pautado no desenvolvimento 
pessoal, em que o indivíduo é entendido como membro de uma coletividade que, através das relações lúdicas, a melhora da qualidade de vida será resultado da interação entre as pessoas e o meio em que vivem (FLORENTINO; CAMARGO, 2015).

Assim sendo, a propagação de ambientes favoráveis à qualidade de vida são necessária para transformar as escolhas saudáveis em escolhas acessíveis, pontos esses primordiais para orientar as práticas desenvolvidas nos grupos de pessoas idosas, como são os grupos de convivência para a terceira idade (DEBERT, 2013).

Os Centros de Convivência (CC) são locais voltados à prevenção da dependência do idoso, da solidão, do isolamento e marginalização social e dos múltiplos problemas de saúde e familiares. Neles, os idosos são instigados a viver a velhice com autonomia, independência, equidade, liberdade, aumentando a autoestima e criatividade, proporcionando novos aprendizados, objetivos, reconquista social e realização pessoal. Um ambiente de refúgio, aconchegante, divertido, criativo, prazeroso e propenso às novas amizades (RAMOS et al., 2016).

Em Teresina, esses locais são ligados às políticas de Assistência Social, sendo denominados Serviços de Convivência e Fortalecimento de Vínculos (SCFV).

\section{Serviços de Convivência e Fortalecimento de Vínculos (SCFV)}

Para o diálogo acerca dos SCFV é necessário conhecimento sobre a Política Nacional do Idoso (PNI) e Política Nacional de Assistência Social (PNAS). A PNI foi promulgada em 1994, com sua regulamentação no ano de 1996. Dez anos após a sua promulgação, a mesma foi readequada para Política Nacional de Saúde da Pessoa Idosa (PNSPI). A presente política assegura os direitos sociais à pessoa idosa, em que condições são criadas para promover sua autonomia, integração e participação efetiva 
na sociedade para reafirmar o direito à saúde nos diversos níveis de atendimento do Sistema Único de Saúde (SUS) (BRASIL, 2006).

A PNAS fornece serviços, programas, projetos e benefícios de proteção social básica e, ou, especial para famílias, indivíduos e grupos que deles necessitarem; contribuindo com a inclusão e a equidade dos usuários e grupos específicos, ampliando o acesso aos bens e serviços socioassistenciais básicos e especiais, em áreas urbana e rural; assegurando que as ações no âmbito da assistência social tenham centralidade na família, e que garantam a convivência familiar e comunitária (BRASIL, 2004).

Os SCFV começam a ser impulsionados após a implantação da PNAS, definindo parâmetros para efetivação dos direitos, concretizados pela Constituição Federal (SOUZA, 2016).

Os SCFV estão organizados de modo a aumentar o arcabouço de trocas culturais e de vivências, produzindo sentimento de pertença e de identidade, fortalecendo vínculos familiares, incentivar a socialização e a convivência comunitária. Possuem caráter preventivo e proativo, fundamentados na defesa e afirmação dos direitos, realçando o desenvolvimento de capacidades e potencialidades, visando o alcance de alternativas emancipatórias para o enfrentamento da vulnerabilidade social (BRASIL, 2014).

Nesse sentido, o SCFV pode ser ofertado em CC, que são unidades públicas ou privadas, vinculadas às entidades de assistência social, com inscrição devida no Conselho de Assistência Social dos municípios (BRASIL, 2015).

Direcionados para indivíduos com 50 anos ou mais, os programas voltados para a terceira idade, como são os CC de idosos, as universidades para a terceira idade e os grupos da melhor idade foram criados na década de 60 , sendo que sua propagação se 
deu basicamente na última década, sendo possível identificar sua presença até mesmo em cidades em que a população idosa é relativamente pequena (DEBERT, 2013).

As principais atividades desenvolvidas, além de contribuírem com a integração social, convivência e participação comunitária, atendem demandas culturais no lazer como, por exemplo, físicos, manuais, intelectuais, artísticos, sociais, turísticos (KIST, 2011; SANTOS; MARINHO, 2015; 2016).

Neste sentido, os Centros de Convivência e Fortalecimento de Vínculos (CCFV) para idosos parecem se mostrar como uma das alternativas favoráveis para a vivência de manifestações culturais nesse âmbito (SANTOS, 2015).

Com base nessas informações, considerando a relevância desses espaços, tornase imprescindível conhecer as atividades realizadas nos CCFV, os profissionais que realizam o acompanhamento dos idosos nos grupos de convivência, bem como as características do uso pelos idosos.

Desta forma, o objetivo deste estudo foi caracterizar as atividades de lazer, seus facilitadores e usuários nos CCFV de Teresina-PI.

\section{Aspectos Teóricos}

\section{Os Conteúdos Culturais do Lazer}

O lazer vem ganhando grande notoriedade na área científica, sob diversas perspectivas, em variadas áreas do conhecimento, levando em consideração seus múltiplos aspectos, nos quais estabelecem relações, apresentando-se como uma grande possibilidade de descanso e divertimento, mas também como elemento essencial para a formação humana, potencializador de transformações sociais. O mesmo é um direito 
social e representação da cidadania, que deve integrar o dia-a-dia de todos os cidadãos, inclusive dos idosos (SANTOS, 2015).

Compreendido como dimensão da cultura, o lazer também se apresenta como uma necessidade do ser humano, que é exercida conforme a vivência lúdica de manifestações culturais, em um campo social conquistado pelo sujeito ou grupo social, onde prevaleçam relações dialéticas com as necessidades, os deveres e os direitos, especialmente com o trabalho produtivo (GOMES, 2014; SANTOS; MARINHO, 2016).

Diante de sua importância, o lazer deve ser programado e executado por diversas instâncias públicas a fim de englobar todo o seu universo como conteúdo de políticas públicas, devido às suas características multidisciplinares. Sendo assim, alguns autores consideram que uma das maneiras de se preencher essa lacuna é adotar ou aderir à intersetorialidade, que é uma nova possibilidade de enfrentar os problemas sociais, com o foco no cidadão e sua totalidade (BONALUME, 2010; RIBEIRO; AMARAL, 2016).

Essas compreensões sobre o lazer corroboram a ideia que geralmente o senso comum tem sobre o fenômeno, de que o lazer está relacionado somente às práticas recreativas, pura e simples (SANTOS; MARINHO, 2016).

Acrescentando informações sobre isso, o lazer possui definições e classificações distintas e suas possibilidades de se manifestar são inúmeras. Para Dumazedier (1980) o lazer é percebido através de cinco áreas fundamentais (conteúdos culturais), como as físicas, manuais, artísticas, intelectuais e sociais que apesar de terem pontos de interesses distintos, convergem para uma conexão entre elas, como por exemplo, um indivíduo pode demonstrar mais de um interesse na mesma atividade de lazer. 
Abordando esses pontos de interesses referentes ao lazer ou as atividades de lazer, Florentino e Camargo (2015) classificam em seus estudos esses conteúdos culturais do lazer em: interesses artísticos (ir ao cinema, ou teatro), intelectuais (voltados para a prática da leitura), físicos (praticar esportes, atividades físicas), manuais (artesanato, atividades manuais) e os interesses sociais (passeios, danças e ouvir músicas, participação de jogos, igrejas, entre outros).

Resumidamente, o conceito de lazer pode ser compreendido como um conjunto de ocupações, em que a pessoa pode entregar-se por livre e espontânea vontade, não importando se seja para repousar, divertir-se, recrear-se e entretiver-se-se ou, ainda, para desenvolver sua informação, sua participação social voluntária ou sua livre capacidade criadora, segundo Dumazedier (1976) após livrar-se ou liberar-se das suas atribuições profissionais, familiares e sociais.

\section{Lazer na Terceira Idade}

Acredita-se que as vivências e práticas da vida cotidiana, especialmente as vivências no lazer, estejam relacionadas à percepção de qualidade de vida dos idosos e sejam determinantes para o aumento das relações sociais destes indivíduos (GONÇALVES et al., 2014).

A participação de grupos de lazer para a terceira idade proporciona um maior contato entre pessoas da mesma idade, possibilitando troca de experiências, melhor percepção sobre própria saúde e satisfação com a vida, menor estresse e sentimento de perda em relação à velhice (ANDRADE et al., 2014; NASCIMENTO JUNIOR; CAPELARI; VIEIRA, 2012). 
Em contrapartida, em um estudo de base populacional realizado com 648 pessoas residentes na região urbana de Montes Claros (MG), foi encontrada alta prevalência de inatividade física no lazer entre idosos (57,1\%). Este nível insuficiente de atividade física impactou negativamente a percepção de qualidade de vida desses indivíduos. Os autores apontam como possível explicação, a diminuição da capacidade funcional na velhice, implicando em mais dependência e menor autonomia dos idosos para a realização de atividades no lazer (OLIVEIRA-CAMPOS; MACIEL; RODRIGUES NETO, 2012).

Vale destacar que a compreensão de que o idoso deve se manter ocupado com atividades de lazer, carrega uma visão instrumental e funcionalista do uso do lazer, descaracterizando-o como direito social que todos os cidadãos têm em relação ao atendimento de suas necessidades. Assim, o idoso passa a ser visto como o foco de programas educacionais, de lazer e turismo, apenas na perspectiva de que é um grupo social a ser controlado e monitorado, principalmente no seu "tempo livre". A criação de programas direcionados a idosos, muitas vezes, estão mais voltados a demandas de contenção e enquadramento social do idoso do que à garantia de seu direito a espaços de sociabilidade, educação e lazer (RODRIGUES, 2015).

\section{Percurso Metodológico}

O referido artigo trata-se de um estudo quantitativo, transversal, realizado em nove CCFV, localizados em diferentes bairros da cidade de Teresina, Piauí, e vinculados à Secretaria Municipal de Cidadania e Assistência Social de Teresina-PI (SEMCASPI). 
Os CCFV pesquisados têm sua execução do serviço na forma direta (executado no próprio Centro de Referência e Assistência Social (CRAS) ou em CC da Administração Pública) e indireta (CC vinculados a entidades ou organizações de assistência social que ofertam os serviços) (BRASIL, 2016).

A população alvo foi constituída por idosos de 60 anos ou mais, cadastrados nos CCFV, e pelos coordenadores desses serviços. Estes foram escolhidos no sentido de favorecer a obtenção das informações relativas aos facilitadores das atividades de lazer junto aos idosos.

A coleta de dados foi realizada de agosto a novembro de 2017 e a amostra de conveniência compreendeu 39 idosos e nove coordenadores ligados aos serviços da base direta e indireta.

Para a coleta de dados utilizou-se a técnica não probabilística por conveniência, em que o pesquisador tem a liberdade de definir sua amostra de maneira mais acessível dentro de sua população (GRDEN et al., 2015, p.1506). A amostra não probabilística foi selecionada, em decorrência do baixo número de idosos com idade igual ou superior a 60 anos, participantes dos CCFV.

Os critérios de inclusão dos participantes foram: (1) idosos com idade igual ou superior a 60 anos; (2) estar cadastrado em um dos nove CCFV de realização da pesquisa; (3) com frequência assídua nos CCFV (aqueles com presença mínima de um mês anterior à coleta); (4) que estivessem presentes no CCFV no momento da coleta; e (5) coordenadores com no mínimo seis meses de atuação no CCFV. Os critérios de exclusão foram: (1) idosos com déficits intelectuais (2) coordenadores afastados por licenças ou de férias. 
Utilizou-se um formulário, constituído por questões objetivas e subjetivas, confeccionadas pelo pesquisador e orientador, com base nos objetivos da pesquisa e considerando outros estudos sobre a temática (RAMOS et al., 2016; SANTOS et al., 2015; PINTO; SILVA, 2016). Além de seguir as normas fundamentadas na Resolução do Conselho Nacional de Saúde de no 466/12 (BRASIL, 2012a) que trata de pesquisas envolvendo seres humanos, por meio do Termo de Consentimento Livre e Esclarecido (TCLE).

Os dados quantitativos foram tabulados e analisados no software GNU PSPP, descritos por medidas de frequência e média.

O consentimento para a realização da pesquisa nas instituições foi previamente solicitado à SEMCASPI, e posteriormente ao Comitê de Ética e Pesquisa (CEP) da Universidade Estadual do Piauí (UESPI), sob o CAAE de nº 66174717.6.0000.5209.

\section{Achados e Reflexões}

\section{Atividades de Lazer Oferecidas nos CCFV}

O Quadro 1 apresenta os serviços oferecidos nos CCFV em Teresina-PI. As atividades estão distribuídas de acordo com as classificações dos conteúdos culturais do lazer em atividades físicas, manuais, artísticas, intelectuais e sociais. 
Quadro 1: Serviços oferecidos nos CCFV em Teresina-PI, 2017.

\begin{tabular}{|c|c|}
\hline CCFV & ATIVIDADES \\
\hline CCFV1 & $\begin{array}{l}\text { Físicas (Capoterapia }{ }^{1} \text {, dança, capoeira, ginástica aeróbica) } \\
\text { Artísticas (Teatro) } \\
\text { Intelectuais (Palestras) } \\
\text { Sociais (Passeios, festas em datas comemorativas) }\end{array}$ \\
\hline CCFV2 & $\begin{array}{l}\text { Físicas (Dança) } \\
\text { Manuais (Oficinas de artesanato) } \\
\text { Artísticas (Coral) } \\
\text { Intelectuais (Palestras) } \\
\text { Sociais (Passeios, festas de aniversário dos usuários, festas em datas comemorativas) }\end{array}$ \\
\hline CCFV3 & $\begin{array}{l}\text { Físicas (Capoterapia e dança) } \\
\text { Intelectuais (Palestras) } \\
\text { Sociais (Passeios, festas em datas comemorativas) }\end{array}$ \\
\hline CCFV4 & $\begin{array}{l}\text { Físicas (Dança, ginástica funcional, capoterapia) } \\
\text { Intelectuais (Palestras) } \\
\text { Sociais (Passeios, festas em datas comemorativas) }\end{array}$ \\
\hline CCFV5 & $\begin{array}{l}\text { Físicas (Capoterapia, recreação) } \\
\text { Intelectuais (Palestras) } \\
\text { Sociais (Passeios, festas em datas comemorativas) }\end{array}$ \\
\hline CCFV6 & $\begin{array}{l}\text { Físicas (Capodance }{ }^{2} \text {, dança, ginástica aeróbica, karatê) } \\
\text { Manuais (Oficinas de artesanato) } \\
\text { Intelectuais (Palestras) } \\
\text { Sociais (Passeios, festas em datas comemorativas) }\end{array}$ \\
\hline CCFV7 & $\begin{array}{l}\text { Físicas (Dança) } \\
\text { Manuais(Oficinas de artesanato) } \\
\text { Sociais (Passeios e festas em datas comemorativas) }\end{array}$ \\
\hline CCFV8 & $\begin{array}{l}\text { Físicas (Dança) } \\
\text { Intelectuais (Palestras) }\end{array}$ \\
\hline CCFV9 & $\begin{array}{l}\text { Físicas (Capoterapia, dança, ginástica localizada) } \\
\text { Manuais (Oficinas de artesanato) } \\
\text { Intelectuais (Culinária, palestras) } \\
\text { Sociais (Passeios, festas em datas comemorativas) }\end{array}$ \\
\hline
\end{tabular}

Fonte: Elaborado pelas autoras, 2017.

Percebe-se que as atividades de lazer relacionadas aos aspectos físicos (capoterapia, dança, capoeira, ginástica aeróbica, ginástica localizada, ginástica funcional, recreação, capodance e karatê) representam as principais atividades realizadas nos centros, totalizando $100 \%(\mathrm{n}=9)$ deles.

\footnotetext{
${ }^{1}$ Modalidade da capoeira, com base lúdica a partir de cantos e roda, composta dos movimentos adaptados a partir da gestualidade característica da luta-ginga, esquiva, roda (LIMA, 2009).

${ }^{2}$ Versão da capoeira que utiliza movimentos típicos da luta, mas com variados gêneros musicais (forró, samba, música eletrônica, etc., de acordo com o relato dos coordenadores dos CCFV investigados).
} 
As atividades manuais (oficinas de artesanato) obtiveram apenas 44,4\% ( $\mathrm{n}=04)$ de representatividade e as atividades artísticas (coral e teatro) corresponderam a $22,2 \%$ $(\mathrm{n}=02)$. Já as atividades intelectuais (palestras e culinária) e as atividades sociais (passeios, festas em datas comemorativas e festas de aniversário dos usuários) obtiveram 88,8\% ( $\mathrm{n}=08)$ cada uma de representatividade, como mostra o (Gráfico 1).

Gráfico1: Atividades de lazer nos CCFV (\%), 2017.

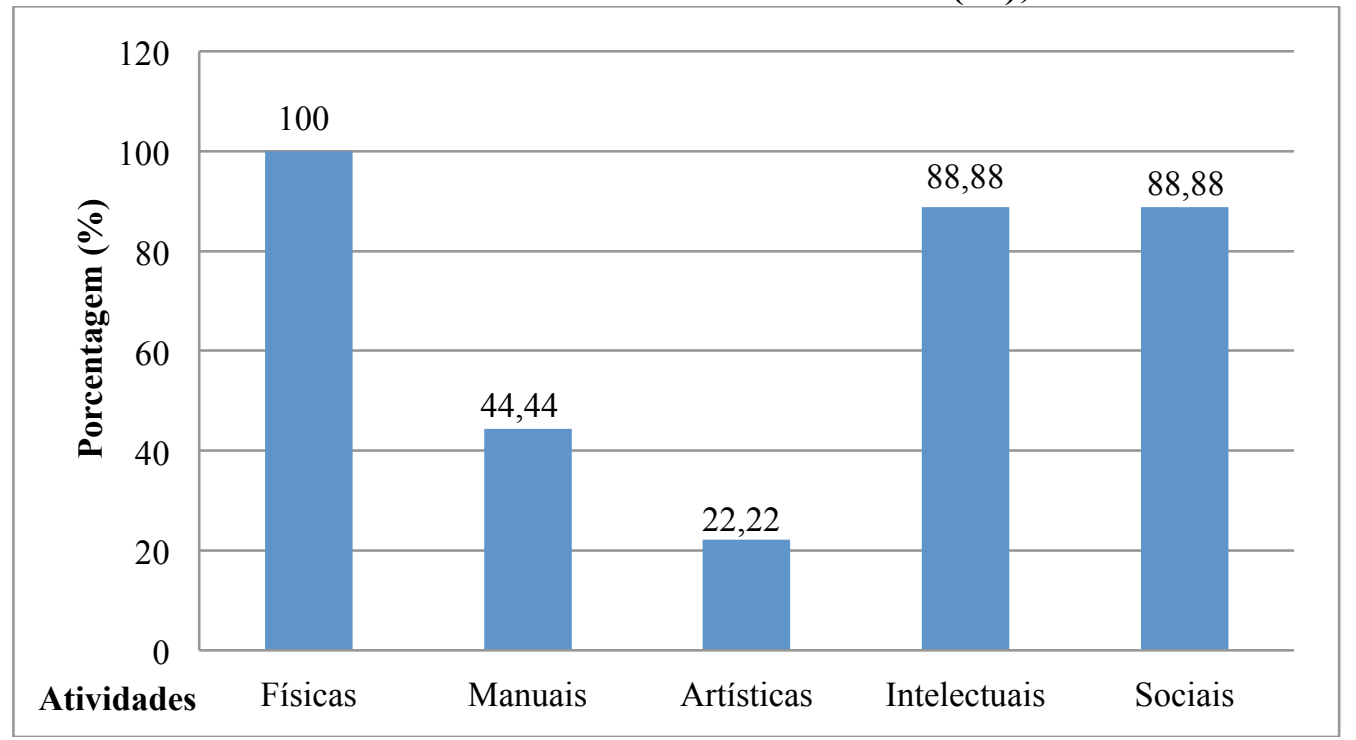

Fonte: Elaborado pelas autoras, 2017.

É importante salientar que viver o lazer em sua diversidade pode contribuir consideravelmente no processo de integração entre os idosos, e destes com demais ciclos de vida e ambientes.

É inegável que existe um arsenal de possibilidades de atividades que podem ser realizadas com idosos em espaços de convivência, em que se podem citar as oficinas de cidadania, oficinas de esporte e lazer, atividades físicas, dinâmicas e jogos coletivos; oficinas artísticas e culturais, pintura, escultura, danças, costura, bijuterias, instrumentos musicais, sessões de cinema, passeios e visitas a equipamentos de cultura, lazer e 
cívicos; conferências, grupos de estudos, teatro, coral, artesanato, passeios turísticos, bailes (BRASIL, 2012b; 2015; DEBERT, 2013; SANTOS; MARINHO, 2016).

No presente estudo, fazendo uma análise entre o Quadro 1 e o Gráfico 1, podemos perceber que as atividades de lazer, relacionadas às atividades físicas, ganham destaque diante das demais, sendo as mais ofertadas nos CCFV. Isso se deve, possivelmente, ao fato de que as práticas corporais/exercícios físicos têm grande procura pelos usuários pelo seu grande potencial lúdico. E ainda pelas necessidades de saúde dos idosos, onde existem muitas indicações médicas, também constatadas aqui neste estudo (OLIVEIRA et al., 2016).

Encontramos semelhanças nas atividades de nosso estudo com os de Minó e Farias (2016), que investigaram a participação de idosos em núcleo de convivência de Viçosa, Minas Gerais. As autoras destacam as atividades físicas, lúdicas e educativas como as maiores demandas do núcleo.

Em relação às atividades intelectuais, observou-se a execução de palestras e cursos de culinária; que segundo os coordenadores, acontecem de forma esporádica. Esse campo das atividades intelectuais constitui-se como um local privilegiado para o oferecimento de informações, debates e etc., sobre diversas temáticas de interesses do CCFV como dos usuários, por exemplo, acesso e serviços socioassistenciais, saúde, educação, esporte, lazer, dentre outros.

Nas atividades com vertente social pode-se apontar que, embora tenhamos encontrado atividades com caráter específico (passeios, festas em datas comemorativas e etc.), damos destaque que esse mesmo conteúdo de lazer (social) esteja agregado em outras atividades do CC, por exemplo, nas atividades físicas (danças, ginásticas, alongamentos e etc.) que são realizadas coletivamente. 
Alguns estudiosos constatam interesses eminentemente sociais em Grupos de Convivência para Idosos (GCI) através de rodas de conversas descontraídas, construídas de forma espontânea entre os participantes dos grupos, antes ou após qualquer atividade, ou, ainda, em intervalos para refeições (SANTOS; MARINHO, 2015).

As atividades manuais (oficinas de artesanato envolvendo confecção de flores, pintura, objetos decorativos, etc.) dos usuários dos SCFV encontrados em nossa pesquisa, diferem um pouco dos encontrados na literatura a cerca de atividades de lazer em GCI, onde se observa atividades envolvendo corte e costura - voltado exclusivamente ao público feminino (ARAÚJO, 2004; LOPES, 2012) e de confecção de redes de pesca; atividade essa desempenhada por homens (SANTOS; MARINHO, 2015).

A realização deste tipo de atividade está relacionada a objetivos subjacentes à realidade social dos usuários dos $\mathrm{CC}$, que demandem a realização de atividades manuais de lazer com foco na geração de emprego e renda. E ainda, de acordo com Santos e Marinho (2015), os homens desempenham esse tipo de atividade pela experiência de sua vida laboral no passado, e que agora, vem sendo difundido por eles a fim de obter recursos financeiros para investir nas atividades turísticas, como os passeios e viagens.

As atividades artísticas (teatro e coral) ocupam poucos momentos nos CCFV de Teresina (Gráfico 1). A explicação para essa questão pode residir no fato de que os centros que desenvolvem tais atividades são os mais antigos e são corriqueiramente convidados a realizarem apresentações em eventos; ou ainda pela falta de profissional capacitado para atuarem nessas duas esferas. 


\section{Perfil Profissional e de Trabalho dos Facilitadores}

A investigação entre os coordenadores dos CCFV de Teresina apontou que a maioria dos facilitadores das atividades nos $\mathrm{CC}$ possui ensino superior completo (45,83\%, n=11), com atuação entre 1 a 2 anos de serviço $(41,67 \%, n=10)$; são terceirizados $(100 \%, \mathrm{n}=24)$, tendo como principais locais de desenvolvimento de suas práticas as salas e pátios $(33,33 \%, \mathrm{n}=03)$. Segundo os coordenadores, o principal desafio para realização das atividades de lazer é a falta de materiais $(55,56 \%, n=05)$, como observado na (Tabela 1).

Tabela 1: Perfil profissional e de trabalho dos facilitadores, 2017.

\begin{tabular}{|c|c|c|}
\hline Formação & TOTAL & $\%(100)$ \\
\hline Ensino superior & 11 & 45,83 \\
\hline Ensino médio & 10 & 41,67 \\
\hline Ensino superior incompleto & 03 & 12,50 \\
\hline TOTAL & 24 & 100 \\
\hline \multicolumn{3}{|l|}{ Tempo de vínculo } \\
\hline$<$ de 1 ano & 01 & 4,17 \\
\hline 1 a 2 anos & 10 & 41,67 \\
\hline 2 a 3 anos & 05 & 20,83 \\
\hline$\geq$ a 3 anos & 08 & 33,33 \\
\hline TOTAL & 24 & 100 \\
\hline \multicolumn{3}{|l|}{ Tipo de vínculo com o CCFV } \\
\hline Terceirizado & 24 & 100 \\
\hline Concursado & 0 & 0 \\
\hline Estagiário & 0 & 0 \\
\hline Outro & 0 & 0 \\
\hline TOTAL & 24 & 100 \\
\hline \multicolumn{3}{|l|}{ Espaços disponíveis } \\
\hline Sala/pátio & 03 & 33,33 \\
\hline Auditório/sala & 02 & 22,22 \\
\hline Sala/pátio/outro & 02 & 22,22 \\
\hline Pátio/outro & 01 & 11,11 \\
\hline Auditório/sala/pátio/outro & 01 & 11,11 \\
\hline TOTAL & 09 & 100 \\
\hline \multicolumn{3}{|l|}{ Principal desafio } \\
\hline Falta de material/recursos & 05 & 55,56 \\
\hline Falta de profissionais & 02 & 22,22 \\
\hline Outro & 02 & 22,22 \\
\hline TOTAL & 09 & 100 \\
\hline
\end{tabular}

Fonte: Elaborado pelas autoras, 2017.

A qualificação profissional dos facilitadores é relevante no que se refere à qualidade das ações oferecidas, pois as atividades voltadas para a promoção/prática do 
lazer dentro dos CCFV exigem constante aperfeiçoamento por parte dos facilitadores, que possuem a incumbência de atender as necessidades dos usuários, e com a finalidade ainda de que se atinja aos objetivos dos CCFV, como por exemplo, a promoção da autonomia, qualidade de vida e etc., da pessoa idosa (BRASIL, 2014).

Autores como Valeriano e Neves Júnior (2014) acreditam que a pós-graduação denota grande importância na formação de um profissional, já que esta proporciona um aprofundamento no conhecimento sobre sua formação acadêmica, onde esse processo gera melhores condições para os profissionais em seu desenvolvimento e atuação no mercado. Há de se destacar que o gestor deve prever momentos de formação permanente dos trabalhadores, preparando-os para desenvolver o seu trabalho de forma criativa (BRASIL, 2015).

Não obstante aos resultados apresentados, o tempo de serviço na instituição também colabora para o estabelecimento e fortalecimento de vínculos entre o usuárioserviço-profissional. Nesse sentido, investigar a trajetória de trabalho, a construção de saberes, ou a própria história de vida dos profissionais, como: suas experiências, suas formações, ideologias e etc., torna-se uma práxis para compreender os fatores que contribuem e influenciam as ações no âmbito profissional (AMORIM FILHO; RAMOS, 2010).

Com relação à estrutura física dos espaços para realização das atividades, percebe-se que as salas e pátios são os ambientes mais utilizados para as práticas de atividades de lazer com os usuários. Nesse momento, destaca-se a importância de outros espaços para o desenvolvimento das práticas de lazer, pois conforme o estudo apontou, existe uma variedade de atividades de lazer acontecendo. E não basta somente proporcionar o lazer pelo lazer, mas tentar alcançar o mínimo de conforto e qualidade 
no desenvolvimento das atividades para os usuários, muitas vezes marcada também pela falta de recursos materiais, pontuado pelos coordenadores desses CCFV.

\section{Perfil Socioeconômico e de Saúde dos Idosos}

Os dados revelaram que os idosos investigados apresentaram uma média de idade de 69,6 anos, 92,31\% são do sexo feminino ( $\mathrm{n}=36), 46,15 \%$ viúvos $(\mathrm{n}=18)$, $23,08 \%$ com ensino fundamental incompleto $(n=9), 89,74 \%$ aposentados/pensionistas $(n=35), 69,23 \%$ recebendo de um a dois salários mínimos $(n=27)$ e 61,54\% vivendo com a família $(\mathrm{n}=24)$ conforme a Tabela 2 apresenta.

Tabela 2: Características sócio demográficas e de saúde dos idosos que frequentam os CCFV em Teresina, 2017.

\begin{tabular}{|c|c|c|}
\hline & & (Continua) \\
\hline CARACTERÍSTICAS & TOTAL (39) & $\%(100)$ \\
\hline \multicolumn{3}{|l|}{ Sexo } \\
\hline Feminino & 36 & 92,31 \\
\hline Masculino & 03 & 7,69 \\
\hline TOTAL & 39 & 100 \\
\hline \multicolumn{3}{|l|}{ Estado Civil } \\
\hline Viúvo & 18 & 46,15 \\
\hline Casado & 13 & 33,33 \\
\hline Separado & 04 & 10,26 \\
\hline Solteiro & 03 & 7,69 \\
\hline União estável & 01 & 2,56 \\
\hline TOTAL & 39 & 100 \\
\hline \multicolumn{3}{|l|}{ Escolaridade } \\
\hline Alfabetizado & 08 & 20,51 \\
\hline Não alfabetizado & 08 & 20,51 \\
\hline Ensino Fundamental & 04 & 10,26 \\
\hline Ensino Fundamental Incompleto & 09 & 23,08 \\
\hline Ensino Médio & 04 & 10,26 \\
\hline Ensino Médio Incompleto & 03 & 7,69 \\
\hline Ensino Superior & 01 & 2,56 \\
\hline Ensino Superior Incompleto & 02 & 5,13 \\
\hline TOTAL & 39 & 100 \\
\hline \multicolumn{3}{|l|}{ Arranjo familiar } \\
\hline Família & 24 & 61,54 \\
\hline Sozinhos & 10 & 25,64 \\
\hline Parentes & 05 & 12,83 \\
\hline TOTAL & 39 & 100 \\
\hline
\end{tabular}




\begin{tabular}{lcc}
\hline Ocupação & & \\
Aposentados/pensionistas & 35 & 89,74 \\
Desempregado & 02 & 5,13 \\
Emprego informal & 02 & 5,13 \\
\hline \multicolumn{1}{c}{ TOTAL } & 39 & 100 \\
\hline Renda & & \\
Nenhum & 02 & 5,13 \\
< de 1 Salário Mínimo & 04 & 10,26 \\
1 a 2 Salários Mínimos & 27 & 69,23 \\
2 a 3 Salários Mínimos & 06 & 15,38 \\
\hline \multicolumn{1}{c}{ TOTAL } & 39 & 100 \\
\hline Patologias & & \\
Hipertensão/Diabetes & 06 & 15,38 \\
Hipertensão/Artrite-artrose-osteoporose & 05 & 12,82 \\
Não tem & 05 & 12,82 \\
Hipertensão & 04 & 10,26 \\
Artrite-artrose-osteoporose & 04 & 10,26 \\
Hipertensão/Depressão & 03 & 7,69 \\
Hipertensão/renite-asma & 02 & 5,13 \\
Labirintite & 02 & 5,13 \\
Diabetes/Artrite-artrose-osteoporose & 01 & 2,56 \\
Tireoide & 01 & 2,26 \\
Enxaqueca & 01 & 2,56 \\
Visual & 01 & 2,56 \\
Auditiva & 01 & 2,56 \\
Respiratória & 01 & 2,56 \\
Digestiva & 01 & 2,56 \\
Insônia & 01 & 2,56 \\
\hline & 39 & 100 \\
\hline Fonte: Elaborado pelas autoras, 2017. & & \\
& &
\end{tabular}

Resultados semelhantes foram encontrados em investigações sobre os níveis de qualidade de vida de idosos participantes de um grupo de convivência de São MamedePB (PAULA et al., 2016), onde 93,3\% dos participantes eram mulheres, e apenas 6,6\% eram homens.

Nesse sentido é comum encontrarmos uma representatividade maior do público feminino nesses espaços, em detrimento do masculino, uma vez que alguns estudos apontam o fato da população masculina e feminina apresentarem ritmos de expectativa de vida diferentes, com características de mortalidade ligadas ao sexo, em que mulheres sobrevivem mais (BERQUÓ, 1996; BRASIL, 2002).

Devido a essa oportunidade de viver mais do que os homens, aumenta a probabilidade das mulheres idosas viverem sozinhas e, consequentemente, a procura por 
uma interação com outras mulheres em situações semelhantes nos grupos de convivência (CAVALCANTE et al., 2015).

E ainda, o público feminino tem uma prática mais efetiva para o autocuidado com a saúde que o público masculino, onde se observa presença reduzida dos homens em ações coletivas, por questões socioculturais e de gênero (JANINI; BESSLER; VARGAS, 2015). Diante disso, Santos e Marinho (2016, p.137) aconselham avaliar a dinâmica nesses espaços, se estas são atrativas para a sua participação, uma vez que sempre estiveram no espaço público, no trabalho, na rua.

Sendo assim, Borges et al.(2008); Pereira (2015) também mostra em pesquisas realizadas em centros de convivência uma população dominada por mulheres, $87 \%$ e $84 \%$ respectivamente.

Essa representatividade feminina se deve a ocasião de que os homens depois que se aposentam apresentam maior dificuldade de se envolver em atividades socioculturais, da educação, lúdica e cultural (PEREIRA, 2015).

Observa-se ainda que o público masculino prefere passar mais tempo em casa, conferindo maior resistência em participar de organizações e lideranças (SANTOS; MARINHO, 2016), em que o homem idoso, possuindo cônjuge, apresenta dificuldades de se manter em uma atividade coletiva se a sua parceira não estiver envolvida. Esse fato passa a ser considerado, portanto, como um aspecto limitante para que os homens desfrutem do lazer na velhice (MELLO; VOTRE, 2013).

Um dado que chama atenção é que grande parte dos idosos moram com a família, e uma minoria, moram sozinhos. Tais achados divergem dos encontrados por Oliveira et al. (2006) e Cavalcante et al. (2015), que apontam um grande percentual de idosas morando sozinhas. Todavia, achados semelhante a esta pesquisa, podem ser 
encontrados nos estudos de Ramos (2003) e Farenzena et al. (2007), nos quais encontraram que apenas $10 \%$ e $13 \%$ dos idosos, respectivamente, moravam sozinhos.

Nesse aspecto, parece que a família se constitui como uma fonte de apoio e incentivo para que o idoso procure fortalecer laços sociais fora do ambiente de casa, o que pode influenciar diretamente no estabelecimento da formação e auto (re)afirmação de sua identidade.

Com relação à escolaridade dos usuários, alguns autores (PAULA et al., 2016) apontam dados semelhantes aos achados desta pesquisa, em que a maioria dos idosos entrevistados $(73,3 \%)$ estudou apenas os primeiros anos do ensino fundamental, sem concluí-lo, e 16,6\% não frequentaram a escola. Esses achados se aproximam aos de outros estudos brasileiros que evidenciaram uma grande parte dos idosos analfabetos ou com baixa escolaridade (HELUANY, 2007).

Essas informações nos fazem perceber a dificuldade em tempos passados ao acesso educacional no Brasil, principalmente para o público feminino, que era limitado esse direito, ficando responsável pelo papel de cuidadora dos filhos e do lar (PAULA et al., 2016; SANTOS; MARINHO, 2016).

Nesse sentido, (re) conhecer o grau de instrução dos participantes desses CCFV é de fundamental importância, para adequação das estratégias, utilizadas nos encontros, ao nível educacional dos usuários facilitando o acesso e o entendimento dos idosos, que poderão usufruir de uma participação mais ativa.

Em relação às patologias que acometem os participantes do $\mathrm{CCFV}$, destaca-se que as principais diagnosticadas foram a hipertensão arterial e a diabetes mellitus $(15,38 \%, \mathrm{n}=06)$, seguida pelo segundo maior acometimento, envolvendo hipertensão e agravos ósseos como artrite, artrose e osteoporose $(12,82 \%, \mathrm{n}=05)$, (Tabela 02$)$. 
Ademais, foi possível identificar resultados semelhantes nos estudos de Silva et al., (2011), que dos agravos diagnosticados entre seus entrevistados em Iguatu-CE, os mais frequentes foram: hipertensão arterial, diabetes mellitus, problemas cardiovasculares, osteoporose, artrose e depressão.

Foi possível verificar também em Navarro e Marcon (2006) que dentre as doenças presentes mais comuns nos idosos participantes de grupos de convivência estão a hipertensão arterial, atingindo $57 \%$ dos idosos, seguida da diabetes mellitus (35,7\%), depressão $(28,6 \%)$ e osteoporose $(21,4 \%)$.

É extremamente salutar, ao se estudar a população idosa, a observação de patologias, principalmente quando se trata de doenças crônico-degenerativas, tendo em vista que a pessoa em processo de envelhecimento tende a ficar mais exposta e sofrer com o impacto que essas doenças causam. Para os CCFV, isso se torna ainda mais importante no tocante ao suporte social, para que se possa estar preparado para atender à demandas sociais, sanitárias, econômicas e afetivas dessa parcela da população.

Além disso, implicará em um diagnóstico precoce de possíveis complicações, estímulo ao autocuidado e orientações sobre práticas saudáveis especificas para este grupo etário (SILVA et al., 2011 ). Cuidado este que não deve ser realizado somente pelas equipes de saúde, mas por todos que estão envolvidos na oferta de atividades de lazer, como é o caso dos CCFV.

Sendo assim, é relevante conhecer esse perfil de saúde dos idosos para que os profissionais que trabalham com esse público possam atender de maneira eficiente as suas necessidades, de acordo com a individualidade biológica de cada um, reforçando ainda a importância de ações intersetoriais, principalmente com o setor saúde. Este, por sua vez possui estratégia de promoção da saúde através do apoio ao autocuidado, 
estímulo à convivência e aprendizado solidário, no sentido de conformação de redes de apoio social (BRASIL, 2015).

\section{Participação (Satisfação, Motivação e Benefícios) dos Idosos nos CCFV}

Analisando a participação dos idosos nos CCFV, verificou-se que a maioria frequenta o serviço há pouco mais de um ano $(35,90 \%, \mathrm{n}=14)$, com uma assiduidade de duas a três vezes por semana $(76,92 \%, n=30)$, mostrando preferências pelas atividades físicas $(97,44 \%, \mathrm{n}=38)$. O principal motivo apontado no estudo para a busca do serviço está relacionado às questões de saúde $(43,59 \%, n=17)$, cujo benefício adquirido com a prática das atividades de lazer é a minimização das dores que relatam sofrer $(30,77 \%$, $\mathrm{n}=12$ ). Tais informações podem ser verificadas na (tabela 3).

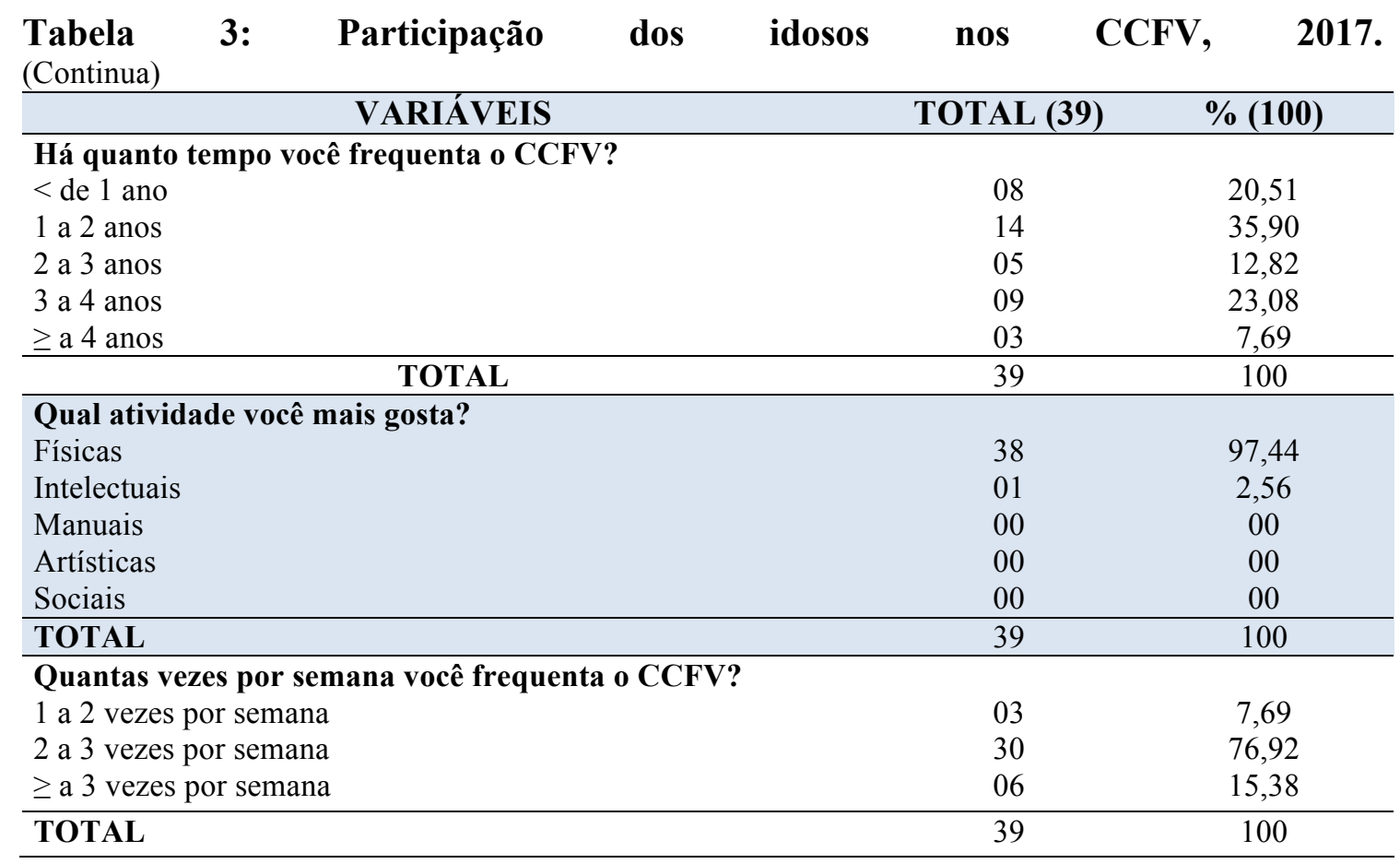




\begin{tabular}{|c|c|c|}
\hline \multicolumn{3}{|c|}{$\begin{array}{l}\text { Qual atividade você gostaria de fazer e que não é oferecida } \\
\text { no CCFV? }\end{array}$} \\
\hline Musculação & 13 & 33,33 \\
\hline Não há & 08 & 20,51 \\
\hline Hidroginástica & 03 & 7,69 \\
\hline Crochê & 02 & 5,13 \\
\hline Artesanato & 02 & 5,13 \\
\hline Gastronomia & 02 & 5,13 \\
\hline Academia ao ar livre & 02 & 5,13 \\
\hline Aulas de violão & 01 & 2,56 \\
\hline Atendimento de psicologia & 01 & 2,56 \\
\hline Zumba & 01 & 2,56 \\
\hline Balé & 01 & 2,56 \\
\hline Atendimento médico & 01 & 2,56 \\
\hline Coral & 01 & 2,56 \\
\hline TOTAL & 39 & 100 \\
\hline \multicolumn{3}{|c|}{ O que motivou você a participar do CCFV? } \\
\hline Saúde & 17 & 43,59 \\
\hline Convite & 06 & 15,38 \\
\hline Solidão & 06 & 15,38 \\
\hline Curiosidade & 04 & 10,26 \\
\hline Interação social & 04 & 10,26 \\
\hline Disponibilidade/aposentado(a) & 01 & 2,56 \\
\hline Saúde/interação social & 01 & 2,56 \\
\hline TOTAL & 39 & 100 \\
\hline \multicolumn{3}{|l|}{ Benefícios das atividades do CCFV } \\
\hline Dores & 12 & 30,77 \\
\hline Interação social & 06 & 15,38 \\
\hline Autoestima & 05 & 12,82 \\
\hline Disposição & 04 & 10,26 \\
\hline Saúde & 04 & 10,26 \\
\hline Depressão & 03 & 7,69 \\
\hline Desempenho motor & 02 & 5,13 \\
\hline Emagrecimento & 01 & 2,56 \\
\hline Doença & 01 & 2,56 \\
\hline Melhora da memória & 01 & 2,56 \\
\hline TOTAL & 39 & 100 \\
\hline \multicolumn{3}{|c|}{ O que dificulta a sua participação no CCFV? } \\
\hline Compromisso & 12 & 30,77 \\
\hline Saúde & 08 & 20,51 \\
\hline Nada & 06 & 15,38 \\
\hline Trabalho & 04 & 10,26 \\
\hline Cuidador & 03 & 7,69 \\
\hline Compromisso-saúde & 02 & 5,13 \\
\hline Afazeres domésticos & 02 & 5,13 \\
\hline Compromisso-trabalho & 01 & 2,56 \\
\hline Saúde-cuidador & 01 & 2,56 \\
\hline TOTAL & 39 & 100 \\
\hline
\end{tabular}

Um estudo realizado em Cajazeiras-PB, abordando a percepção de idosos sobre grupo de convivência, verificou que o tempo de participação dos encontros nos grupos 
de convivência foi de seis e dez anos (42\%) (ANDRADE et al., 2014), apresentando assim um tempo de participação maior do que o exposto nessa investigação.

Ainda em relação à participação dos idosos no grupo de convivência, o estudo de Borges et al., (2008) apontou que a maioria (41,62\%) frequentava os grupos há mais de 5 anos, onde apenas 4,21\% estavam à menos de 1 ano.

O tempo de participação nos $\mathrm{CC}$ parece repercutir também nos níveis de atividades físicas dos idosos. Embora não seja um objetivo dessa investigação, mas é relevante destacar que há pesquisas que corroboram que idosos participantes de centros de convivência são ativos (MAZO et al., 2005), e outras pesquisas em que não se observa associação estatística significante quanto ao nível de atividade física e a participação em grupos de convivência (BENEDETTI; MAZO; BORGES, 2012).

A frequência marcada de 2 a 3 vezes por semana (tabela 3) dos idosos às atividades ajudam ainda no alcance dos objetivos dos CCFV, pois é importante que a periodicidade dos encontros dos grupos seja regular, haja vista que têm por finalidade fortalecer vínculos familiares, incentivar a socialização e a convivência comunitária (BRASIL, 2016).

No tocante à preferência dos idosos pelas atividades físicas, é comum reconhecer esse interesse para além da ludicidade dessas atividades, porque as práticas corporais nos espaços de convivência tornam-se uma opção de lazer economicamente acessível para pessoas de baixa renda, ou para aqueles que desfrutam de baixas aposentadorias e/ou pensões (ANDRADE et al., 2014).

Essa prioridade talvez possa ser explicada pelos benefícios da prática dos exercícios, amplamente difundidos na sociedade, auxiliando na melhora da capacidade funcional, colaborando na normalização da pressão arterial, reduzindo o risco de 
doenças cardiovasculares, osteoporose, diabetes mellitus, entre outras, além de contribuir psicossocialmente, como no combate da depressão, melhora na autoestima e autoconfiança (VIDMAR et al., 2011; COSTA et al., 2015), fatores estes que legitimam a indicação da prática dos exercícios pelos médicos aos idosos.

Corroborando os interesses apontados nesse estudo, outras investigações apontaram que a maioria dos idosos $(96,8 \%, n=339)$ tinham preferências pelas atividades físicas (VALIM-ROGATTO, et al., 2010) e especificamente no conteúdo dança $(50 \%, n=30)$ (ANDRADE et al.,2014). Diferente dos resultados apontados por Santos e Marinho (2016), que explorando os conteúdos de lazer e participação de homens em centros de convivência encontraram as atividades turísticas como sendo as mais frequentes realizadas com o público idoso.

Nesse estudo, uma parcela dos idosos $(33,33 \%, n=13)$ assinalou a musculação como sendo uma atividade que poderia ser realizada no CCFV. Essa musculação referese a exercícios resistidos, com a utilização de aparelhos (halteres, tornozeleiras, bastões e etc.). Sendo assim, informações de novas possibilidades de atividades podem servir como fortes estratégias na diversificação das atividades de lazer nos CCFV de Teresina, uma vez que os idosos sugerem práticas às quais possuem interesses de vivenciar, como hidroginástica, crochê, gastronomia, prática de exercícios em academia ao ar livre, aulas de violão e etc.

Essa "sugestão" concorda com os documentos institucionais que tratam dos objetivos dos CCFV, sobre ampliar as trocas culturais e de vivências entre os usuários, assim como desenvolver o seu sentimento de pertença e de identidade; além de contribuir no planejamento das atividades que deve ser realizado coletivamente, envolvendo os profissionais que atuam nos serviços e os usuários (BRASIL, 2016). 
Os motivos para adesão aos CCFV assemelham-se aos dos autores Xavier et al. (2015), demonstrando que as principais razões dos idosos, na procura do grupo, são as condições de viver com apoio à saúde, a construção de vínculos afetivos e o compromisso social, de ser presente nos encontros. Diferindo dos resultados apresentados por Santos et al. (2015), a despeito dessas razões, o maior estímulo para a entrada nos GCI foi proveniente de fontes externas, principalmente de convite de conhecidos/amigos; o estímulo/convite de esposas/companheiras ou de mulheres coordenadoras/integrantes dos grupos.

Minó e Farias (2016) também verificaram que as atividades desenvolvidas nos CC fazem bem aos idosos, em termos de saúde, por meio da melhora da socialização e comunicação desses.

Nesse sentido, os dados nos permitem inferir que os CCFV contribuem na qualidade de vida dos idosos. Destaca-se mais uma vez que a prática de exercícios físicos contribui no melhoramento da aptidão física, facilitando o desenvolvimento das atividades diárias desse público, como eles mesmos apontam nessa investigação.

Todavia, somente a realização de atividade física nos espaços de convivência não é suficiente para fazer parte do escopo de atividades desenvolvidas pelos CC. É necessário fomentar informações sobre seus benefícios, desenvolver avaliação das condições, necessidades e expectativas das pessoas idosas em relação a uma mudança de comportamento (TOSCANO; OLIVEIRA, 2009). E isso se torna possível quando há uma equipe de profissionais que entendam e tenham respaldo técnico para realizar essas demandas; e como se pode constatar nesse estudo, existe uma parcela de facilitadores sem formação acadêmica (ensino médio). 
Nessa investigação, quando perguntados sobre o que dificulta a participação desses idosos nos CCFV, os mesmos apontaram os compromissos $(30,77 \%, n=12)$ e a saúde $(20,51 \%, \mathrm{n}=08)$ como principais motivos. Esses compromissos, dizem respeito à responsabilidade de ir fazer compras, pagar contas pessoais e de familiares (pois não enfrentam filas), terem que ficar em casa para receber um parente ou amigo, ou realizar serviços domésticos.

Esses motivos são apresentados em ordem inversa nos estudos de Salin et al., (2011), em sua maioria, nos casos dos problemas de saúde, estes se sobressaem aos fatores externos. Pois é sabido que a maioria dos idosos que frequentam espaços de convivência apresenta saúde fragilizada, em que na maioria das vezes, durante o processo de envelhecimento, enfrentam graves problemas (ANDRADE et al., 2014).

Por fim, uma das maneiras de minimizar esses desafios, tanto dos serviços quanto dos usuários talvez seja a promoção/melhoramento do acesso e ações intersetoriais, em especial das políticas de educação, saúde, cultura, esporte e lazer existentes no território dos $\mathrm{CC}$, que consequentemente contribui para o usufruto dos usuários aos demais direitos, fortalecendo os objetivos dos SCFV, no que diz respeito à independência, empoderamento e autonomia da pessoa idosa (BRASIL, 2015).

\section{Reflexões Finais}

O presente estudo apontou que os cincos conteúdos culturais do lazer (físicos, manuais, intelectuais, artísticos e sociais) são desenvolvidos desigualmente nos CCFV de Teresina. As atividades de lazer relacionadas aos aspectos físicos (capoterapia, dança, capoeira, ginástica aeróbica, ginástica localizada, ginástica funcional, recreação, capodance e karatê) representam as principais atividades realizadas nos centros, 
totalizando $100 \%(\mathrm{n}=9)$ deles. $\mathrm{O}$ processo natural de envelhecimento e às doenças crônicas que costumam acometer os idosos e provocar limitações físicas, estimula a aproximação destes com as atividades físicas no seu tempo de lazer, com intuito de minimizar limitações ou patologias.

Foi possível identificar ainda que os usuários dos CCFV são constituídos em sua maior parte por mulheres $(92,31 \%, \mathrm{n}=36)$. Nesse sentido, o presente estudo abre espaço para reflexão sobre quais metodologias deve-se (re)construir para aproximar o público masculino desses espaços de atividades de lazer.

Acredita-se que a realização de novos estudos possa contribuir para compreensão da temática investigada, entendendo ainda que o fortalecimento das ações e parcerias intersetoriais pode ser um caminho possível para o alcance e execução dos objetivos dos SCFV e aumentar o alcance na execução de atividades relativas a todos os conteúdos culturais do lazer.

Talvez a aproximação da Estratégia Saúde da Família (ESF) dos CCFV, possa contribuir com as atividades desenvolvidas nos CCFV, seja com atividades de educação em saúde, tratando sobre práticas corporais, acometimentos crônicos, alimentação saudável, qualidade de vida, estímulo à convivência, aprendizado solidário e etc., já que se constitui de equipe multiprofissional, além, de também conhecer algumas singularidades de seu território (CONCEIÇÃO; MORAES; FRANCHINI, 2014).

Como já apresentado ao longo desse trabalho, os grupos de convivência atuam objetivando a interação social entre os frequentadores e a sociedade, através de suas diversas atividades que sirvam de incentivo na interação do idoso com seus colegas, ou até mesmo com outros grupos, tornando-o ativo e independente. 
Por fim, a pessoa idosa possui anseios, desejos, vontades de experimentar novas possibilidades, e luta para quebrar alguns estereótipos, como os de que não possuem mais nenhuma utilidade na sociedade. Enquanto ser humano merece ser ouvido e respeitado, atendido em seus direitos, precisa e pode ser estimulado a vivenciar novos desafios. Isso poderá contribuir na ressignificação de sua cidadania, da sua qualidade de vida e independência. Desta forma, os CCFV precisam ser qualificados a fím de oferecer todas as possibilidades de lazer aos idosos, contribuindo assim, na sua autonomia e cidadania.

\section{REFERÊNCIAS}

AMORIM FILHO, M.L.; RAMOS, G.N.S. Trajetória de vida e construção dos saberes de professores de educação física. Revista Brasileira de Educação Física e Esporte, São Paulo, v.24, n.2, p.223-38, 2010.

ANDRADE, A.N. et al. Percepção de idosos sobre grupo de convivência: estudo na cidade de Cajazeiras-PB. Rev. Bras. Geriatr. Gerontol., Rio de Janeiro, v.17, n.1, p.39-48, 2014.

ARAÚJO, V.N.F. Os coordenadores de grupos de convivência de idosos como facilitadores da construção da cidadania. 2004. $116 \mathrm{f}$. Dissertação (Mestrado em Serviço Social) - Centro Socioeconômico, Universidade Federal de Santa Catarina, Florianópolis, 2004.

BENEDETTI, T.R.B; MAZO, G.Z; BORGES, L.J. Condições de saúde e nível de atividade física em idosos participantes e não participantes de grupos de convivência de Florianópolis. Ciência \& Saúde Coletiva, v.17, n.8, p.2087-2093, 2012.

BERQUÓ, E. S. Algumas considerações demográficas sobre o envelhecimento no Brasil. In: Seminário Internacional sobre o Envelhecimento Populacional. Brasília, 1996. Brasília: Ministério da Previdência e Assistência Social, 1996.

BORGES, P. L. C. et al. Perfil dos idosos frequentadores de grupos de convivência em Belo Horizonte, Minas Gerais, Brasil. Caderno de Saúde Pública, Rio de Janeiro, v. 24, n. 12, p.2798-2808, 2008. 
BONALUME, C.R. O Esporte e o lazer na formulação de uma política pública intersetorial para a juventude: a experiência do PRONASCI. Brasília, 2010. Disponível

em: https://repositorio.unb.br/bitstream/10482/6068/1/2010_ClaudiaReginaBonalume.pdf . Acesso em: 15 out. 2016.

BRASIL, Ministério da Saúde. Portaria n².528 de 19 de outubro de 2006. Política Nacional de Saúde da Pessoa Idosa, 2006. Disponível em: https://bvsms.saude.gov.br/bvs/saudelegis/gm/2006/prt2528_19_10_2006. Acesso em: 06 out. 2016.

Política Nacional de Assistência Social. Ministério do desenvolvimento social e combate a fome: Secretaria Nacional de Assistência Social. Brasília, 2004. Disponível em:

http://www.mds.gov.br/webarquivos/publicacao/assistencia_social/Normativas/PNAS2 004.pdf. Acesso em: 11 out. 2016.

. Ministério do Desenvolvimento Social e Combate à Fome. Perguntas Frequentes: Serviço de Convivência e Fortalecimento de Vínculos (SCFV). Brasília, 2015. Disponível em: https://mds.gov.br/assistencia-social-suas/servicos-eprogramas/servicos-de-convivencia-e-fortalecimento-de-vinculos . Acesso em: 13 out. 2016.

BRASIL, Ministério do Desenvolvimento Social e Combate à Fome. Tipificação dos Serviços Socioassistenciais. Brasília, 2014. Disponível em: https://www.mds.gov.br/webarquivos/publicacao/assistencia_social/Normativas/tipifica cao.pdf.Acesso em: 13 out. 2016.

Ministério do Desenvolvimento Social e Combate à Fome. Serviços de Convivência e Fortalecimento de Vínculos para pessoas idosas - Orientações Técnicas. Brasília, 2012b. Disponível em: http://craspsicologia.files.wordpress.com/2013/09/orientacoes-tecnicas-do-scfv-parapessoas-idosas.pdf. Acesso em: 13 out. 2016.

Conselho Nacional de Saúde. Resolução $n^{\circ} \mathbf{4 6 6 / 1 2}$ sobre pesquisa envolvendo seres humanos. Brasília: MS, 2012a.

Ministério do Planejamento, Orçamento e gestão. Instituto Brasileiro de Geografia e Estatística - IBGE. Perfil dos idosos responsáveis pelo domicílio no Brasil. Rio de Janeiro: IBGE, 2002.

Ministério do Desenvolvimento Social e Combate à Fome Secretaria Nacional de Assistência Social - SNAS. Caderno de Orientações: Serviço de Proteção e Atendimento Integral à Família e Serviço de Convivência e Fortalecimento de Vínculos. Articulação necessária na Proteção Social Básica, Brasília, 2016.

CAVALCANTE, R.M.F. et al. Contribuições de um Grupo da Terceira Idade para a saúde das Idosas Participantes. R bras ci Saúde, v.19, n.1, p.11-18, 2015. 
CONCEIÇÃO, M. R.; MORAES, C. C.; FRANCHINI, M. L.; Políticas públicas de saúde, atenção primária e interdisciplinaridade - a produção de cuidado nas práticas corporais. Cad. Edu. Saúde e Fís. v.1, n.1; 2014.

COSTA, L.S.V. et al. Análise comparativa da qualidade de vida, equilíbrio e força muscular em idosos praticantes de exercício físico e sedentários. Revista Faculdade Montes Belos (FMB), v.8, n.3, p.61-179, 2015.

DEBERT, G.G. Feminismo e velhice. Sinais Sociais, Rio de Janeiro, v.8, n.22, p.15-38, 2013.

DUMAZEDIER, J. Valores e conteúdos culturais do lazer. São Paulo: SESC, 1980.

Lazer e cultura popular: Debates. São Paulo: Perspectiva,1976.

FARENZENA WP. et al. Qualidade de vida em um grupo de idosas de Veranópolis. Revista Kairós, v.10, n.2, p.225-43, 2007.

FLORENTINO, I.M.; CAMARGO, M.J.G. Atividades de lazer no contexto hospitalar: uma estratégia de humanização. Revista Brasileira de Estudos do Lazer. Belo Horizonte, v.2, n.2, p.99-114, 2015.

GOMES, C.L. Lazer: necessidade humana e dimensão da cultura. Revista Brasileira de Estudos do lazer, Belo Horizonte, v.1, n.1, p.3-19, 2014.

GONÇALVES, K. C.; et al. Comparação entre a percepção da qualidade de vida e o nível de aptidão física de idosos praticantes de atividades aquáticas. Rev Bras Ciênc Saúde. v. 12, n. 39, p. 35-43, 2014.

GRDEN, C.R.B. et al. Características sociodemográficas e de acesso de longevos aos serviços de saúde. Cienc Cuid Saude, v.14, n.4, p.1505-1512, 2015.

Heluany, C. C. V. Perfil do envelhecimento de octogenários e nonagenários residentes em Siderópolis -SC. 2007. 114f. Dissertação (Mestrado em Ciências da Saúde) - Programa de Pós-graduação em ciências da Saúde, Universidade do Extremo Sul Catarinense, Criciúma (SC), 2007.

INSTITUTO BRASILEIRO DE GEOGRAFIA E ESTATÍSTICA (IBGE). Número de idosos cresce $18 \%$ em 5 anos e ultrapassa 30 milhões em 2017. Disponível em: http://agenciadenoticias.ibge.gov.br/agencia-noticias/2012-agencia-denoticias/noticias/20980-numero-de-idosos-cresce-18-em-5-anos-e-ultrapassa-30milhoes-em-2017. Acesso em: 21 dez. 2018.

JANINI, J.P; BESSLER, D; VARGAS, A.B. Educação em saúde e promoção da saúde: impacto na qualidade de vida do idoso. Saúde em Debate. Rio de Janeiro, v.39, n.105, p.480-490, 2015.

KIST, R.B.B. Os grupos de convivência em Porto Alegre e sua contribuição à garantia de direitos e à autonomia de homens e mulheres idosos: Uma aproximação com os centros de idosos em Barcelona. Porto Alegre, 2011. 
LIMA, M. C. A ginga dos mais vividos. Brasília: Mano Lima, 2009.

LOPES, M.A. Pessoas longevas e atividade física: fatores que influenciam a prática. Florianópolis, 2012.

MAZO GZ. et al. Nível de atividade física, condições de saúde e características sócio demográficas de mulheres idosas brasileiras. Ver Port Cien Desp, v.5, n.2, p.202-212, 2005 .

MELLO,J.G.; VOTRE, S.J. Fatores que interferem na participação de homens idosos em programas de esporte e lazer. Pensar a Prática. Goiânia-GO, v.16, n.4, p.956-1270, 2013.

MINÓ, N.M; FARIAS, R. C. P. Percepção de idosos sobre núcleo de convivência: um estudo com participantes do programa municipal da terceira idade de Viçosa, Minas Gerais, Brasil. Rev. Educ., Cult. Soc., Sinop/MT/Brasil, v.6, n.1, p.302-317, 2016.

NASCIMENTO JUNIOR, R. A.; CAPELARI J. B.; VIEIRA, L. F. Impacto da prática de atividade física no estresse percebido e na satisfação de vida de idosos. Rev Educ Fis. v. 23, n. 4, p. 647-654, 2012.

NAVARRO, F.M.; MARCON, S.S. Convivência familiar e independência para atividades de vida diária entre idosos de um centro dia. Cogitare Enferm, v.11, n.3, p.211-7, 2006.

OLIVEIRA-CAMPOS, M.; MACIEL, M. G.; RODRIGUES NETO, J. F. Atividade física insuficiente: fatores associados e qualidade de vida. Rev Bras Ativ Fis Saúde. v. 17, n. 6, p. 562-572, 2012.

OLIVEIRA, K.L et al. Relação entre ansiedade, depressão e desesperança entre grupos de idosos. Psicologia em estudo, v.11, n.2, p.351-359, 2006.

OLIVEIRA, D.A.S. et al. Participação de idosas em grupos sociais: qualidade de vida e capacidade funcional. Rev Rene, v.17, n.2, p.278-84, 2016.

PAULA, C.L.M. et al. Qualidade de vida de idosos participantes de um grupo de convivência no munícipio de São Mamede - PB. Revista Brasileira de Educação e Saúde, Pombal, PB, v.6, n.2, p.01-07, 2016.

PEREIRA, M. M. Qualidade de vida e nutrição em idosos participantes de centros de convivência da terceira idade. 2015. 102 f. Dissertação (Mestrado em Infectologia em Saúde Pública) - Programa de Pós-graduação em Ciências da Coordenadoria de Controle de Doenças, Secretaria de Estado da Saúde de São Paulo, São Paulo, 2015.

PINTO, E.M.; SILVA, J.P.C. Lazer na juventude: compreensão e prática, no município de Santa Cruz do Capibaribe - PE. Cinergis, Santa Cruz do Sul, v.17, n.1, p.09-14, 2016. 
RAMOS LR. Fatores determinantes do envelhecimento saudável em idosos residentes em centro urbano: Projeto Epidoso, São Paulo. Cadernos de Saúde Pública, v.19, n.3, p.793-98, 2003.

RAMOS, S.S.S. et al. Participação de idosos em um centro de convivência na cidade de Santana/AP: perfil dos indivíduos e características de participação. Revista Madre Ciência Saúde, v.1, n.1, 2016.

RIBEIRO, O.C.F.; AMARAL, S.C.F. Entre o lazer esportivo participativo e ambiental e o lazer turístico - as políticas públicas de lazer em Brotas/SP. Movimento, Porto Alegre, v.22, n.1, p.63-74, 2016.

RODRIGUES, M. C. A configuração do lazer no espaço das universidades da terceira idade. Estud. interdiscipl. envelhec. v. 20, n. 3, p. 771-787, 2015.

SALIN, M.S. et al. Atividade Física para idosos: diretrizes para implantação de programas e ações. Rev. Bras. Geriatr. Gerontol., Rio de Janeiro, v, 14, n.2, p.197208, 2011.

SANTOS, P.M. Lazer e grupos de convivência para idosos: um estudo sobre a participação de homens em Florianópolis (SC). Licere, Belo Horizonte, v. 18, n.3, 2015.

SANTOS, P.M.; MARINHO, A. Conteúdos culturais do lazer e participação masculina em grupos de convivência para idosos de Florianópolis (SC). Licere, Belo Horizonte, v.18, n.4, 2015.

- Grupos de convivência para idosos como espaços de lazer (também) para homens: o olhar dos coordenadores em Florianópolis (SC). Motrivivência, v.28, n.47, p.128-144, 2016. Disponível em: http://www.google.com.br/url?sa=t\&rct=j\&q=\&esrc=s\&source=web\&cd=2\&ved=0ahU KEwiv_puLqOjPAhUJIZAKHeaAAhsQFgglMAE\&url=https $\% 3 \mathrm{~A} \% 2 \mathrm{~F} \% 2 \mathrm{Fperiodicos.}$ ufsc.br\%2Findex.php\%2Fmotrivivencia $\% 2$ Farticle $\% 2$ Fdownload $\% 2 F 2175$ 8042.2016v28n47p128\%2F31823\&usg=AFQjCNFvWhshV1zzT0LKBmNsiF44SJty5Q . Acesso em: 26 set. 2016.

et al. Lazer e participação de homens em grupos de convivência para idosos de Florianópolis (SC): motivações e significados. Revista Kairós Gerontologia, São Paulo, v.18, n.3, p.173-191, 2015.

SILVA, H.O. et al. Perfil epidemiológico de idosos frequentadores de grupos de convivência no município de Iguatu, Ceará. Rev. Bras. Geriatr. Gerontol., Rio de Janeiro, v.14, n.1, p.123-133, 2011.

SOUZA, A.L. Serviços de convivência e fortalecimento de vínculos na relação família e sociedade. Lisboa, 2016.

TOSCANO, J.J.O; OLIVEIRA, A.C.C. Qualidade de Vida em idosos com distintos níveis de atividade Física. Rev Bras Med Esporte, v.15, n.3, 2009. 
VALERIANO, R.J.; NEVES JUNIOR, C.L. Diversidade nas aulas de educação física das escolas públicas de Araxá-MG. Evidência, Araxá, v.10, n.10, p.61-74, 2014.

VALIM-ROGATTO, PC. et al. Participação de idosos em atividades físicas, sociais, educacionais e em serviços de saúde de centro de convivência: diferenças entre sexos. Coleção Pesquisa em Educação Física, v.9, n.3, 2010.

VIDMAR, M. F. et al. Atividade física e qualidade devida em idosos. Revista Saúde e Pesquisa, v.4, n.3, p.417-424, 2011.

XAVIER, L.N. et al. Grupo de convivência de idosos: apoio psicossocial na promoção da Saúde. Rev Rene, v.16, n.4, p.557-66, 2015.

\section{Endereço das Autoras:}

Edirlane Soares do Nascimento

Rua Manoel Borges de Andrade, 190 - Bairro Dirceu Arcoverde

Parnaíba - PI - 64.210-360

Endereço Eletrônico: edirlane1105@hotmail.com

Juliêta Lopes Fernandes

Rua José Olímpio Ramos, 485 - Bom Lugar

Floriano - PI - 64.804-490

Endereço Eletrônico: julyyeta_fernandes@hotmail.com

Thaís Norberta Bezerra de Moura

Av. Dr. Aquiles Wall Ferraz, Quadra - A, Casa 23 - Morada do Sol

Teresina - PI - 64.053-500

Endereço Eletrônico: thaisinha_moura@hotmail.com

Maria Luci Esteves Santiago

Rua Quincas Bastos, 2100 - Três Andares

Teresina - PI - 64.017-580

Endereço Eletrônico: mles_@hotmail.com 